\title{
Rigid and Flexible Coupling Analysis of Crankshaft System
}

\author{
Jinhe Lv ${ }^{1, a}$, Yaxu Chu ${ }^{2, b^{*}}$ and Zengming Feng ${ }^{3, c}$ \\ ${ }^{1}$ College of Automobile \& civil Engineering of Beihua University \\ 2 The Office of Academic Affairs of Beihua University \\ ${ }^{3}$ College of Mechnical Science and Engineering of Jilin University \\ avjinhe_1987@163.com, bcyx_1964@sina.com, ${ }^{\mathrm{c}} 543207353 @ q q . c o m$ \\ * The Corresponding Author
}

Keywords: Crankshaft assembly; Finite element; Multibody dynamics; Rigid flexible coupling

\begin{abstract}
In this paper, the combined method of finite element and multi-body dynamics is used to study the crankshaft assembly. The article first uses the finite element software to carry out the connecting rod the reliability of the connecting rod is proved by the state analysis. Then the regularity of crankshaft assembly motion is verified through the multi-body dynamics analysis of the crankshaft assembly rigid body, and finally, the law of the movement of the crankshaft assembly is discussed. The crankshaft assembly is coupled to the rigid flexible coupling analysis to study the load variation and dynamic characteristics of the key parts of the crankshaft assembly. Simulation analysis shows that: the connecting rod stress and deformation in the limit range, to verify the reliability of the connecting rod; the piston motion acceleration increases with the mixed gas deflagration pressure becomes larger, the variation of load of rigid bearing spindle neck in crankshaft main bearing the same; compared with the crankshaft assembly of rigid support, flexible support reduce the crankshaft load.
\end{abstract}

\section{Introduction}

The crankshaft is the engine of complex process and high cost of parts, by the rotation inertia force in the working process and the interaction of cylinder pressure, prone to torsional vibration, and the work load is big, the crankshaft is prone to fracture damage in the work process, it is necessary to carry out real-time monitoring on the strength of the key parts of the crankshaft ${ }^{[1]-[4]}$. With the engine power and light development, crankshaft assembly traditional research method makes the model simplification is dynamic analysis modal analysis and static analysis of crankshaft and crank assembly of multi rigid body, can not be real-time monitoring of crankshaft by variation of load. Therefore, the dynamic characteristics of the crankshaft assembly are analyzed by the combination of multibody dynamics and finite element method ${ }^{[5]}$.

\section{The Finite Element Analysis of The Connecting Rod}

Three Dimensional Model of Connecting Rod. In this paper, the three-dimensional model of the connecting rod is drawn by CATIA. The three-dimensional model of the connecting rod is divided into three parts: the connecting rod big head, the connecting rod small head, the connecting rod rod body. ${ }^{[6]}$ The connecting rod bolt and the positioning pin have little influence on the calculation of the chapter, so the is ignored in the modeling and grid division. Fig. 1 is shown as a three-dimensional model of the connecting rod. 


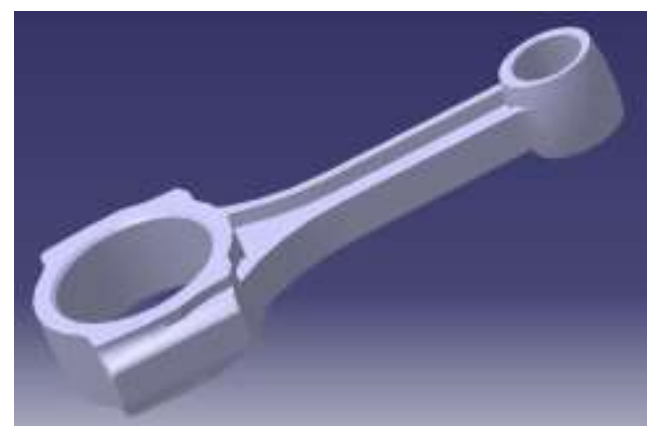

Figure 1. Connecting rod finite element model

Grid Division and Loading Load. The connecting rod head, head and body of the connecting rod is provided over the corner, the lower end of the connecting rod and head and excessive fillet, and connecting rod structure is irregular, so using automated grid method adaptable grid is more suitable for the connecting rod, the connecting rod mesh as shown in Fig. $2^{[7]}$. In order to carry out the static analysis of the connecting rod, the mixing gas deflagration when connecting rod under stress, because the big head and the connecting rod are respectively by crankshaft and pin the role of stress, so $-\mathrm{Z}$ direction force is exerted on the connecting rod at the lower end, $\mathrm{Z}$ is applied in the direction of the upper connecting rod force.

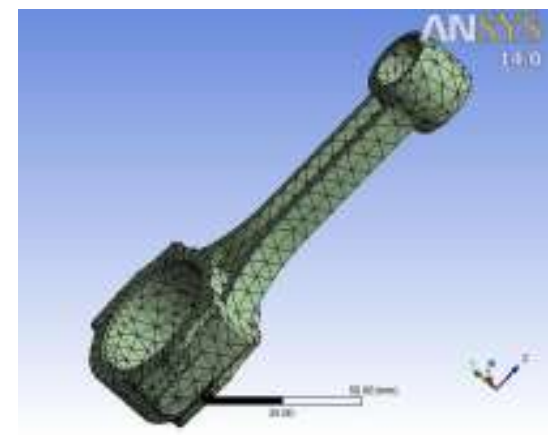

Figure 2. Connecting rod mesh model

Finite Element Analysis.As can be seen from Fig. 3, the stress is mainly concentrated at the small head of the connecting rod, and the maximum pressure is $44.679 \mathrm{MPa}$, as shown by the standard $\mathrm{A}$ in the figure. The force of the connecting rod small head is concentrated at the lower end, the maximum pressure is $34.76 \mathrm{MPa}$, the force of the connecting rod head is concentrated on the upper end, and the maximum pressure is $14.922 \mathrm{MPa}$.

The force and deformation of the connecting rod is shown in Fig. 4. From the B shown in the figure, we can see that due to the pressure of the connecting rod pin acting on the lower end of the connecting rod small head, the connection between the connecting rod body and the connecting rod small head will produce relatively large deformation, and the deformation amount is $0.0018 \mathrm{~mm}$. The deformation of the whole connecting rod body decreases gradually from the small end of connecting rod to the large end of connecting rod due to the small section of connecting rod small head and large cross-section structure of connecting rod. 


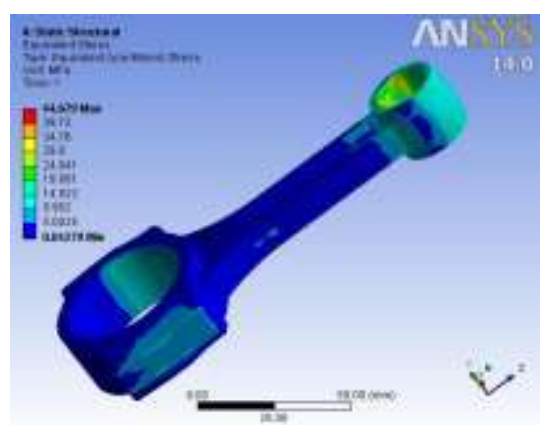

Figure 3. Connecting rod stress cloud map

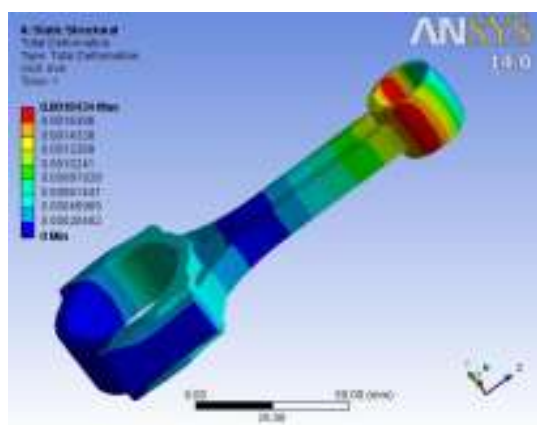

Figure 4. Connecting rod strain cloud map

\section{Establishing Rigid and Flexible Coupling Model of Crankshaft Assembly}

Three Dimensional Model of Crankshaft Assembly.To accurately analyze the dynamic characteristics of crankshaft assembly system, it is necessary to establish the correct crankshaft assembly model. The whole crankshaft assembly includes crankshaft, flywheel, connecting rod, piston, cylinder block, main bearing and other components. In this paper, the three-dimensional solid model of the crankshaft assembly is established by the size of each component and the assembly relationship in the CATIA software, as shown in Fig. 5.

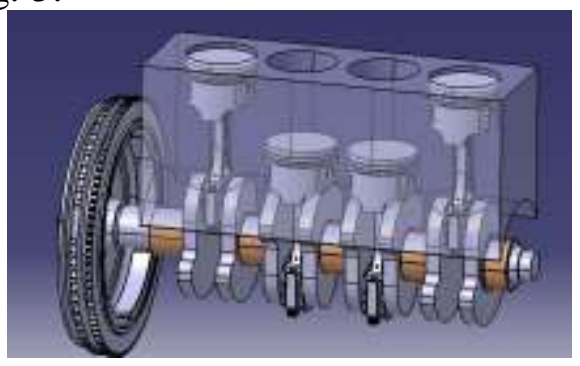

Figure 5. 3D Solid model of crankshaft assembly

The Establishment of Finite Element Model. In this paper, crankshaft and piston are set into flexible parts, and other parts are rigid bodies. Therefore, only the crankshafts and pistons are meshed in HyperMesh software. The total number of nodes of crankshaft is 5650, the total number of units is 19185 , the total number of piston nodes is 2786 , and the total number of units is 8813 , as shown in Fig. 6andFig. 7, the mesh generation model of crankshaft and piston.

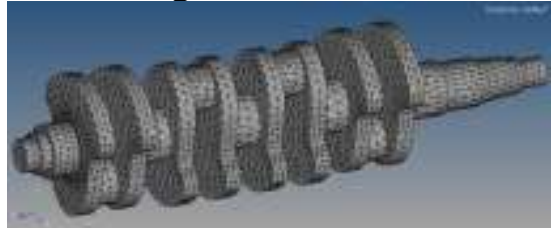

Figure 6. Gridding model of crankshaft

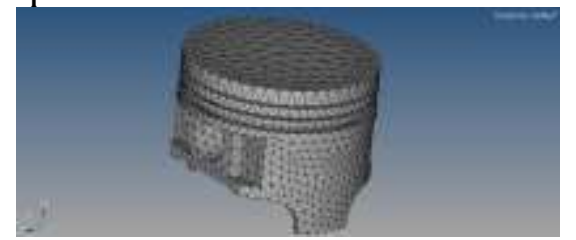

Figure 7. Piston mesh

Establishment of Rigid Flexible Coupling Model. Although the multi-body dynamics software RecurDyn modeling tool has the ability, but the limitations of the larger, but the software provides a seamless interface with the most mainstream CAD software through the interface can be three-dimensional entity model into RecurDyn software, as shown in Fig. 8 for the rigid flexible model into crankshaft assembly. 


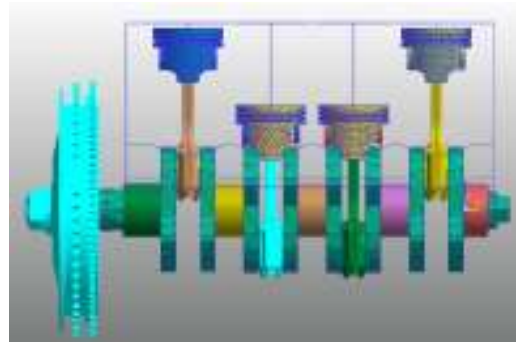

Figure 8. Rigid and flexible coupling model of crankshaft assembly

Set up the Constraint and Load the Load. In the rigid flexible coupling model of crankshaft assembly, the contact between the piston and cylinder, pin, crankshaft, main bearing and connecting rod is between the flexible body and rigid body. Therefore, the contact between flexible body and rigid body (Fsurface-Surface) is chosen in this paper. The contact force between the flexible body and the rigid body is formed, and the flexible body is the action surface (action surface) and the rigid body is the base surface (base surface). The article use the same load spectrum, therefore the coverage of the same load exerted on the piston top.

Analysis of Simulation Results. As can be seen from Fig. 9, the maximum load of each pin shaft hole appeared to produce the greatest pressure in the mixed gas deflagration of the moment, because each cylinder load, so the pin shaft hole by roughly the same trend of load. The pin shaft bore bears the deflagration pressure and the pin shaft gravity of the mixture, so the load on the pin shaft hole is close to the maximum pressure produced by the mixture gas deflagration, and the maximum load of each cylinder piston is $20000 \mathrm{~N}$.

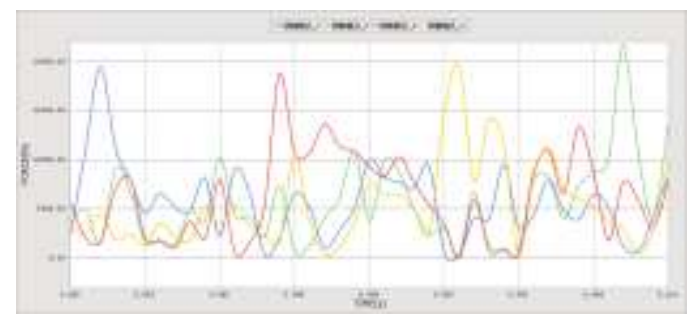

Figure 9. Load of shaft bore of piston pin

As can be seen from Fig. 10, the maximum pressure at the neck of each connecting rod appears at the time of deflagration, and the maximum load is almost the same, about $27000 \mathrm{~N}$. In addition to other gas deflagration time, the crankshaft connecting rod journal force is relatively stable, and the load trend of the connecting rod journal corresponding to each cylinder is almost the same, and the load increases with the increase of speed.

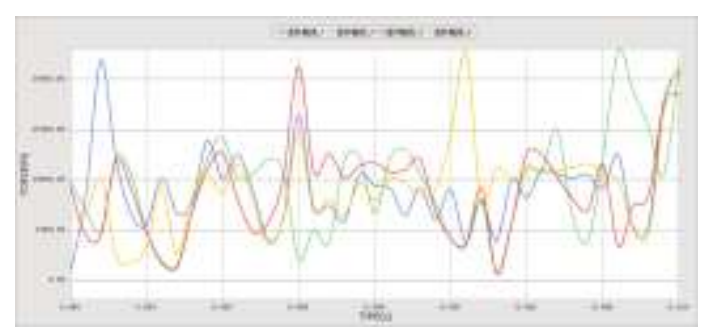

Figure 10. The load of the crankshaft of the crankshaft

As shown in Fig. 11 for the crankshaft main bearing load, the main bearing load peak occurs in the mixed gas deflagration moment, the maximum value of the main bearing load is about $1600 \mathrm{~N}$, indicating that the crankshaft load is assigned to the other shaft neck, and firing two cylinder shaft the neck connecting shaft adjacent the load is larger. Compared with rigid support, crankshaft flexible support significantly reduces the load of crankshaft journal neck, and the load variation trend of each spindle neck is approximately the same, which makes the crankshaft parts more evenly distributed. 


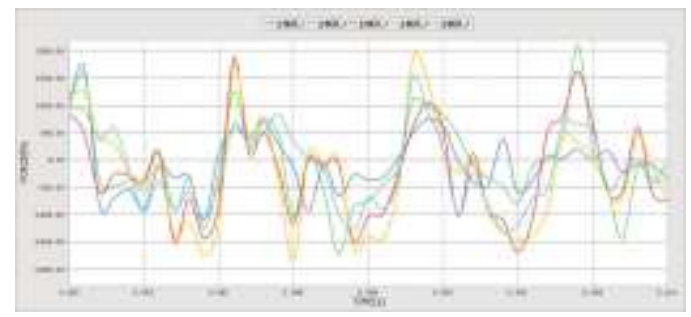

Figure 11. Main journal load

\section{Conclusion}

The crankshaft neck of the crankshaft is subjected to the large head pressure, self gravity and rotating inertia force of the connecting rod, so that the load of the crankshaft is larger than that of the pin shaft.

With the increase of the deflagration pressure of the mixture, the acceleration of the piston increases gradually. Compared with the rigid support, the flexible support significantly reduces the load bearing capacity of the crankshaft spindle, and the force is uniform.

As the pressure of main bearing increases, the oil film thickness decreases. When the oil film thickness is zero or negative, it shows that the main shaft neck and main bearing have dry friction or mixed friction.

\section{Acknowledgements}

The 13th Five-year Science and technology project of Education Department of Jilin Province(JJKH20170030KJ)

\section{References}

[1] J.Y. Ping,C.Z Qin L.Wei and H. Kun "Optimization Design Study on Dynamic Parametersfor Engine Crankshaft," journal of north university of china (Natural science edition), vol.38, pp. 155-160, April 2017.

[2] W.H Jun and Y.X Hua , "The Crankshaft Design Optimization of Turbo Engine based on CAE Analysis," Small Internal Combustion Engine and Vehicle Technique, vol. 46, pp.46-49, February 2017

[3] Peng L, Shizhao N, Zheng W, Ziwei J, Jianwu Y, Zhongxiang Q, Wangmo P. Predicting durations of online collective actions based on Peaks' heights [J]. Communications in Nonlinear Science and Numerical Simulation. 2018, 55: 338-354.

[4] Z.Li."Dynamics Optimizing Design of Four Cylinders Crankshaft Based on Parameterization,", instrument technology, vol.50,pp.80-83.January 2016

[5] Z.Wei,L.R.Dong, "Dynamic characteristic based on modal superposition method and structure optimization of crankshaft" Transactions of the Chinese Society of Agricultural Engineering, vol.31,pp.129-136. February 2015

[6] S.L.Ke,T.Bin, and X.D.X.in. "FEA Optmial Design of Diesel Engine Crankshaft," Tractor \& Farm Transporter, vol.34, pp.54-56, June 2017.

[7] L.Z.Hui,X.Wei and L.H.Rui "Fatigue strength optimization design of crankshaft for turbocharged gasoline engine," Journal of Mechanical \& Electrical Engineering, vol. 30, pp. 807-810, July 2013

[8] W.X.Hua,C.Z.Jun,Z.Teng“Application of CAD Technology in Crankshaft Design” Agricultural Equipment\&Vehicle Engineering, vol.12, pp.43-45, December2017. 